\title{
An Injection Solution of Dapsone
}

T. M. FRENCH, в.PHARM.

Pharmaceutical Department, I'niversity College Hospital, London

Dapsone is normally administered orally but occasionally oral therapy cannot be tolerated and a preparation suitable for injection is required. Until recently a preparation for intramuscular injection was available under the name of Avlosulfon Soluble but it is no longer marketed. Avlosulfon Soluble consisted of a water soluble derivative of Dapsone which is not easy to prepare in the hospital pharmacy. Dapsone itself has a very low solubility in water and the only official formulation, which was contained in the British National Formulary 1963, consisted of a suspension of Dapsone in arachis oil. Oily injections are however inconvenient to use and may irritate the tissues.

The following formulation contains Dapsone dissolved in a water-miscible vehicle.

Dapsone 5 g. (100 mgm. in $2 \mathrm{ml}$.)

Absolute Alcohol $\quad 40 \mathrm{ml}$.

Benzyl Alcohol $5 \mathrm{ml}$.

Propylene Glycol to $100 \mathrm{ml}$.

The Dapsone is dissolved in the absolute alcohol, benzyl alcohol added and then pro- pylene glycol to volume. The solution, after filtration and filling into $2 \mathrm{ml}$. ampoules, is sterilised by autoclaving. Because the efficiency of autoclaving is much reduced in the absence of water the ampoules are sterility tested before use. Work is in progress to determine whether water can be introduced into the formulation without affecting stability, thus increasing the efficiency of the sterilisation process.

This solution is suitable for intramuscular injection, the benzyl alcohol being incorporated to reduce pain on injection. After storage for 9 months in the dark, analysis of the solution shows no significant loss of potency, though slight darkening occurs; the therapeutic activity is also unimpaired after this time.

\section{ACKNOWLEDGEMENT}

My thanks are due to Dr. W. H. Jopling, Consultant Leprologist, Hospital for Tropical Diseases, who originally encouraged this work, and has commented on its therapeutic efficacy. 